\title{
Association between Hemiarthroplasty vs. Total Hip Arthroplasty and Major Surgical Complications among Patients with Femoral Neck Fracture
}

\author{
Takahisa Ogawa ${ }^{1,2,3, *}$, Toshitaka Yoshii ${ }^{1, *}$, Mutsuko Moriwaki ${ }^{4}$, Shingo Morishita ${ }^{1}$,

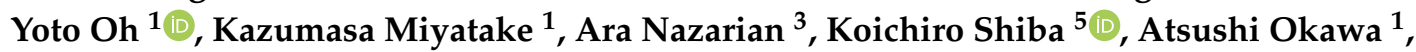 \\ Kiyohide Fushimi ${ }^{6}$ and Takeo Fujiwara ${ }^{2}$ (i) \\ 1 Department of Orthopedic Surgery, Tokyo Medical and Dental University Graduate School of Medicine, \\ Tokyo 113-8519, Japan; morsorth@tmd.ac.jp (S.M.); oh.orth@tmd.ac.jp (Y.O.); miyatake.orj@tmd.ac.jp (K.M.); \\ okawa.orth@tmd.ac.jp (A.O.) \\ 2 Department of Global Health Promotion, Tokyo Medical and Dental University Graduate School of \\ Medicine, Tokyo 113-8519, Japan; fujiwara.hlth@tmd.ac.jp \\ 3 Center for Advanced Orthopaedic Studies, Department of Orthopaedic Surgery, Beth Israel Deaconess \\ Medical Center, Harvard Medical School, Boston, MA 02215, USA; anazaria@bidmc.harvard.edu \\ 4 Department of Tokyo Metropolitan Health Policy Advisement, Graduate School of Medicine, Tokyo Medical \\ and Dental University, Tokyo 113-8510, Japan; mmoriwaki.qmc@tmd.ac.jp \\ 5 Department of Epidemiology, Harvard T.H. Chan School of Public Health, Boston, MA 02115, USA; \\ Shiba_k@g.harvard.edu \\ 6 Department of Health Policy and Informatics, Graduate School of Medicine, Tokyo Medical and Dental \\ University, Tokyo 113-8510, Japan; kfushimi.hci@tmd.ac.jp \\ * Correspondence: takahisa.o@gmail.com (T.O.); yoshii.orth@tmd.ac.jp (T.Y.)
}

Received: 6 September 2020; Accepted: 30 September 2020; Published: 3 October 2020

\begin{abstract}
Previous studies have shown better clinical outcomes after total hip arthroplasty (THA) compared to hemiarthroplasty (HA) for displaced femoral neck fracture. However, few studies have focused on the surgical risks of the two procedures. Therefore, we investigated the perioperative complications of HA and THA in femoral neck fracture, using a large nationwide inpatient database. A total of 286,269 patients (281,140 patients with HA and 5129 with THA) with a mean age of 81.7 were enrolled and HA and THA patients were matched by a propensity score to adjust for patient and hospital characteristics. Patients in a matched cohort were analyzed to compare complications and mortality. The systemic complication rate was not significantly different after a propensity score matching of 4967 pairs of patients. However, the incidence of both hip dislocation and revision surgery was more frequent in the THA group (Risk difference (RD), 2.74; 95\% Confidence interval (CI), 2.21-3.27; $p<0.001 ; \mathrm{RD}, 2.82 ; 95 \% \mathrm{CI}, 2.27-3.37 ; p<0.001$, respectively). There was no significant difference in 30 day in-hospital mortality among the two groups. The risk of dislocation and reoperation was higher for THA than for HA in elderly patients with a femoral neck fracture in this retrospective study using a nationwide database.
\end{abstract}

Keywords: Femoral neck fracture; total hip arthroplasty; hemiarthroplasty; national database; National Registration Database; complications; hip dislocation; geriatric fractures

\section{Introduction}

Femoral neck fracture is a representative trauma causing disability and morbidity, especially among elderly people. Open reduction and internal fixation often result in poor outcomes, and either hemiarthroplasty (HA) or total hip arthroplasty (THA) is recommended for displaced femoral neck 
fractures [1,2]. Previous studies have found that functionally demanding patients occasionally have problems after HA, such as pain, acetabular erosion, or implant loosening which, consequently, requires revision surgery. Recent studies have demonstrated the superior clinical outcomes of THA compared to HA [3-10]. However, the HA procedure is generally less extensive than the THA procedure. The average age of patients who require surgery also becomes higher, as the aging population increases, which could contribute to increased risk of surgical complications [11-14]. Therefore, when making decisions regarding surgical procedures, surgeons need to consider surgical extensiveness and complications in addition to functional outcomes.

Previous studies have reported that THA requires a greater amount of blood transfusion than HA $[1,6,8,15]$ and that it could be associated with a higher incidence of perioperative complications $[16,17]$. However, other studies reported no differences in the complication rate between the two procedures [5,6]. It is difficult to obtain robust conclusions about surgical risks as most studies investigating femoral neck fracture are relatively small case series and have primarily investigated local complications. Some studies have evaluated systemic complications after surgery for displaced femoral neck fracture. However, those investigations did not match the baseline characteristics, such as age and health status, and thus the result between HA and THA patients could be biased. We aimed at comparing HA and THA in terms of perioperative complications, including local complications as well as systemic complications, using a large national inpatient database. Moreover, we performed a propensity score matching analysis to minimize confounding effects.

\section{Materials and Methods}

\subsection{Data Source}

We used the Japanese Diagnosis Procedure Combination inpatient database, which includes discharge abstracts and administrative claims data for 1549 acute care hospitals, covering $90 \%$ of all tertiary-care emergency hospitals in Japan. Patient baseline characteristics; main diagnoses for admission, activity of daily life score and comorbidities presented on admission, and complications after admission; surgical procedures coded with Japanese original codes; and length of hospital stay were the data contained in this database. Medical diagnosis, comorbidity, and complications were coded with the International Classification of Disease and Related Health Problems Tenth Revision codes (ICD-10) [18] (Tables A1 and A2). A previous study validated the database of these diagnostic and procedural records with approximately $80 \%$ sensitivity and $90 \%$ specificity [19]. Approval for this study was obtained from the institutional review board (M2000-788). The requirement to obtain informed consent from individual patients was waived due to the anonymized data.

\subsection{Study Population}

The cohort comprised all consecutive patients hospitalized with a primary diagnosis of femoral neck fracture (ICD-10, S7200) who underwent surgery, either HA (HA, K0811; K-code, which is an originally developed national operation code) or THA (THA, K0821), between 1 April 2011 and 31 March 2018. Patients more than 60 of age were included.

\subsection{Main Exposure}

The surgical approaches were categorized into hemiarthroplasty (K0811) and THA (K0821).

\subsection{Clinical Outcomes}

We investigated 30 day in-hospital mortality and postoperative complications. Postoperative complications contained both systemic complications and local complications. The following complications - coronary heart disease, heart failure, respiratory disorders, pulmonary embolism, stroke, renal failure, urinary tract infection, sepsis, intensive care unit (ICU) admission, and blood transfusion-were included as systemic complications, and we defined revision surgery, hip dislocation, 
surgical site infection, and debridement procedure as local complications. We accessed revision surgery as a surgery coded as hemiarthroplasty (K0811) or total hip arthroplasty (K0821) after the HA or THA index. We also investigated anesthesia time, length of hospital stay, and daily average medical cost.

\subsection{Covariates}

Data on age, gender, body mass index (BMI), smoking history, comorbidities at admission, activity of daily life (ADL) score upon patient admission, hospital bed size, and annual hospital surgical volume for hip fracture surgery were evaluated. We defined hospital surgical volume as the annual number of patients undergoing hip fracture procedures at each hospital [20]. BMI was categorized as less than 18.5 , from 18.5 to $24.9,25.0$ to 29.9 , and more than $30.0 \mathrm{~kg} / \mathrm{m}^{2}$. Congestive heart failure, peripheral vascular disease, myocardial infarction, heart failure, peripheral vascular disease, stroke, dementia, pulmonary disorders, peptic ulcer, mild, moderate, and severe disease, diabetes with or with complications, hemiplegia, renal failure, cancer, metastatic cancer, HIV, hypertension, stable angina, Parkinson's disease, and anemia were the comorbidities that we evaluated upon admission based on the components of the Carlson Comorbidity Index [21]. The ADL assessment was performed by calculating the Barthel Index (BI). The BI is an ordinal scale that measures ADL performance and total $\mathrm{BI}$ is a cumulative score of these 10 items [22]. A maximum score of 100 corresponds to complete independence, and a minimum score of 0 corresponds to total dependence.

\subsection{Statistical Analysis}

Propensity score matching was used to identify a cohort of patients with similar baseline characteristics to account for differences in baseline characteristics between the two groups of eligible participants. A propensity score is the conditional probability of having a specific exposure such as HA versus THA on a set of baseline measured covariates [23,24]. We estimated the propensity score using a multivariable logistic-regression model, with THA as the dependent variable and all the baseline characteristics described in Table A3 as covariates. Then we matched patients in the HA and THA groups with a 1:1 matching protocol without replacement. We set caliper width for matching equal to 0.2 of the standard deviation of the logit of the propensity score. We estimated standardized differences for all the baseline covariates before and after matching to assess rematch baseline. Standardized differences of less than $10 \%$ for a given baseline covariates indicate relatively balanced matching [25]. For the comparative risk of other postoperative complications-anesthesia time, length of hospital stay, and daily average medical cost—we used a Generalized Estimating Equations(GEE)s and calculated percent absolute risk differences (\% absolute risk difference (RD), with 95\% confidence intervals (CI)). In the matched cohort, we plotted survival curves for revision surgery using the Kaplan-Meier method and compared patients undergoing HA vs. THA using the log-rank test. A Cox regression model with robust variance estimator was used to estimate the time to revision surgery during hospitalization. The type I error probability was set to 0.05 for all analyses. All statistical analyses were performed using Stata version 16.1 (Stata Corp, College Station, TX, USA).

\subsection{Sensitivity Analyses}

We conducted sensitivity analyses and used a stabilized inverse probability weight model, instead of propensity score matching, to account for confounding.

\section{Results}

\subsection{Study Population}

A total of 286,269 patients (mean (Standard Deviation(SD)) age, 81.7 years (8.40years)) who underwent arthroplasty, 281,140 (98.2\%) who underwent HA, and $5129(1.8 \%)$ who underwent THA, were included, of which 222,993 (77.9\%) were women. Mean follow-up was 37.4 days. Compared to patients undergoing HA, patients undergoing THA were younger (HA, mean (SD) 81.8 (8.32) vs. 
THA, 73.6 (8.72); standardized mean difference (SMD), 95.9\%) and had a higher BMI (25-30; 8.4\% vs. 13.2\%; SMD, 15.7\%). They had fewer comorbidities such as heart failure (7.1\% vs. $4.1 \%$; SMD, $13.1 \%)$, hypertension ( $34.8 \%$ vs. $29.7 \%$; SMD $10.9 \%$ ) history of stroke (10.4\% vs. $5.9 \%$; SMD, $16.2 \%)$, and dementia (16.5\% vs. $7.1 \%$; SMD, $29.5 \%$; Table 1, Table A3). The THA group included patients with higher ADL scores (19.55 vs. 33.43; SMD, $43.8 \%$ ) and longer waiting time ( $>72$ hours) for surgery (50.8\% vs. $66.4 \%$; SMD, $32 \%$ ) as well as more patients who underwent surgery at both large and teaching hospitals ( $8.2 \%$ vs. $14.6 \%$; SMD, $20.2 \%$; $2.8 \%$ vs. $10.3 \%$; SMD, $30.5 \%$, respectively) with general anesthesia (56.5\% vs. $70.1 \%$; SMD, $28.5 \%$ ) than the HA group. Patients with osteoarthritis before hip fracture more likely underwent THA than HA ( $0.1 \%$ vs. $6.7 \%$; SMD, $36.8 \%)$.

Table 1. Patient characteristics.

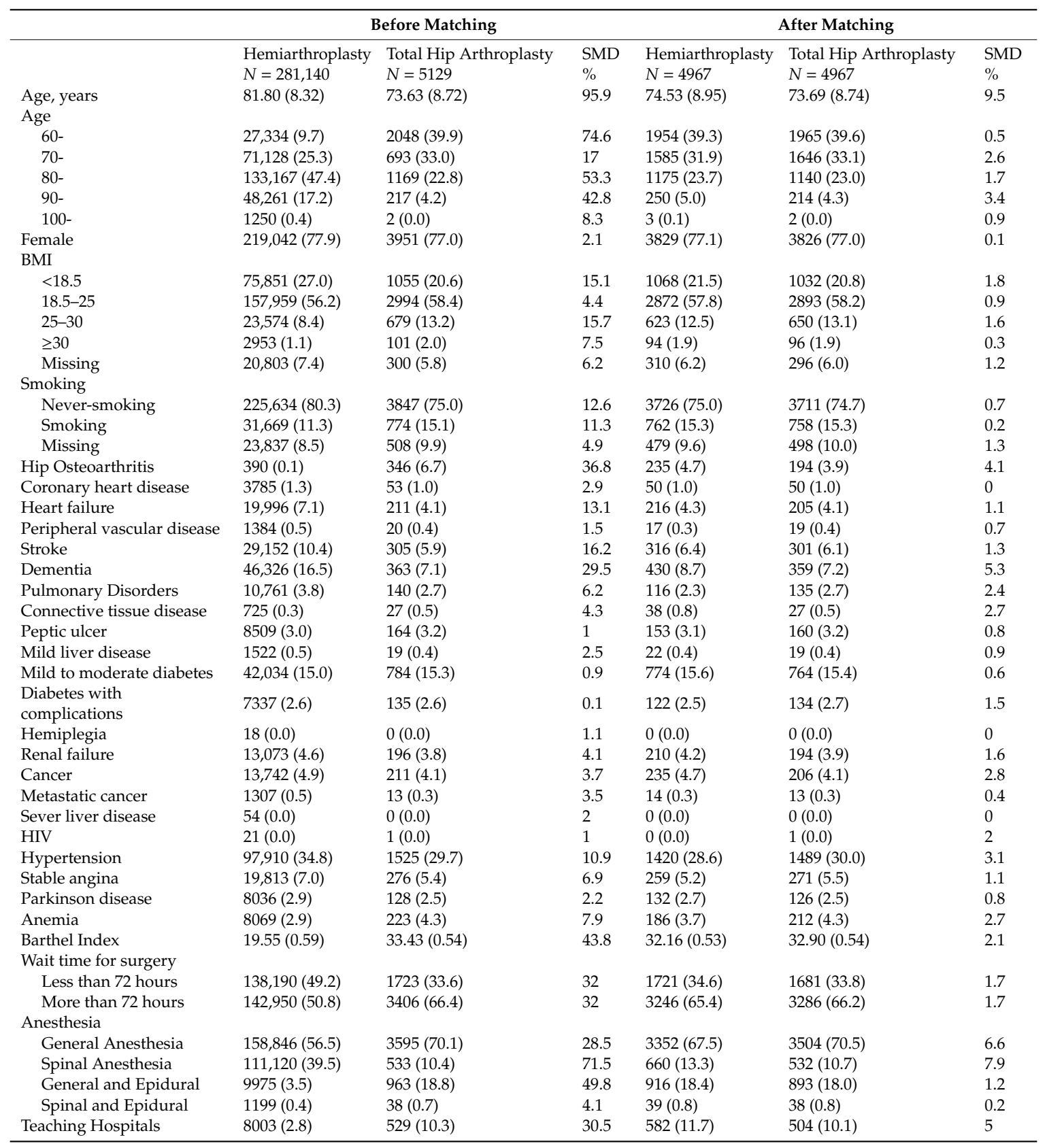


Table 1. Cont.

\begin{tabular}{|c|c|c|c|c|c|c|}
\hline & & Before Matching & & & After Matching & \\
\hline \multicolumn{7}{|l|}{ Hospital Volume, bed } \\
\hline$<100$ & 49,585 (17.6) & $599(11.7)$ & 16.9 & $612(12.3)$ & $583(11.7)$ & 1.8 \\
\hline $100-200$ & $87,074(31.0)$ & $1,437(28.0)$ & 6.5 & $1,321(26.6)$ & $1388(27.9)$ & 3 \\
\hline $300-400$ & $35,514(12.6)$ & $644(12.6)$ & 0.2 & $622(12.5)$ & $623(12.5)$ & 0.1 \\
\hline $400-500$ & $20,552(7.3)$ & $523(10.2)$ & 10.2 & $516(10.4)$ & 509 (10.2) & 0.5 \\
\hline$>500$ & $23,070(8.2)$ & 749 (14.6) & 20.2 & $761(15.3)$ & $719(14.5)$ & 2.4 \\
\hline 30 100 case/year & $123,221(43.8)$ & $2377(46.3)$ & 5.1 & $2259(45.5)$ & $2302(46.3)$ & 1.7 \\
\hline $100 \sim$ case/year & $138,415(49.2)$ & $2246(43.8)$ & 10.9 & $2126(42.8)$ & $2177(43.8)$ & 2.1 \\
\hline
\end{tabular}

The values are given as the number of patients, with the percentage of the cohort in parentheses, with the exception of age, and Barthel Index, which are given as the mean and standard deviation. BMI, body mass index; HIV, human immunodeficiency virus; $N$, number of patients; SMD, standardized mean difference.

\subsection{Outcomes after Matching}

A total of 4967 pairs of patients undergoing HA and THA were obtained after propensity score matching. A standardized difference among two groups was less than $10 \%$ for all covariates and this suggests matching agreed achieved balance (Table 2). Patients undergoing THA were significantly associated with local complications (306 patients $(6.2 \%)$ vs. 116 patients $(2.3 \%)$; absolute risk difference, RD, 3.83; 95\%CI, 3.04-4.61; $p<0.001$ ) but not mortality (RD, $0.08 ; 95 \% \mathrm{CI},-0.24-0.4 ; p=0.62$ ) and systemic complications $\left(\mathrm{RD},-0.26 ; 95 \% \mathrm{CI},-1.39-0.86 ;^{\wedge}=0.65\right)$ compared to patients undergoing $\mathrm{HA}$, after the matching, as shown in Tables 2 and 3.

Table 2. Postoperative complications between the propensity score matched groups.

\begin{tabular}{|c|c|c|c|c|}
\hline & $\begin{array}{l}\text { Hemiarthroplasty } \\
(N=4967) \\
N(\%)\end{array}$ & $\begin{array}{l}\text { Total Hip Arthroplasty } \\
(N=4967) \\
N(\%)\end{array}$ & $\begin{array}{l}\text { Absolute Risk Difference } \\
\text { (95\% Confidence Interval } \\
\text { (CI)), \% }\end{array}$ & $p$-Value \\
\hline Systemic complications & $464(9.3)$ & $451(9.1)$ & $-0.26(-1.39-0.86)$ & 0.65 \\
\hline Local complications & $116(2.3)$ & $306(6.2)$ & $3.83(3.04-4.61)$ & $<0.001$ \\
\hline \multicolumn{5}{|l|}{ Systemic complications } \\
\hline Coronary Heart Disease & $62(1.2)$ & $50(1.0)$ & $-0.24(-0.66-0.17)$ & 0.25 \\
\hline Heart Failure & $46(0.9)$ & $38(0.8)$ & $-0.16(-0.51-0.19)$ & 0.37 \\
\hline Respiratory Disorders & $102(2.1)$ & $78(1.6)$ & $-0.48(-1-0.04)$ & 0.07 \\
\hline Pulmonary Embolism & $19(0.4)$ & $23(0.5)$ & $0.08(-0.18-0.34)$ & 0.54 \\
\hline Stroke & $28(0.6)$ & $20(0.4)$ & $-0.16(-0.43-0.11)$ & 0.25 \\
\hline Renal Failure & $16(0.3)$ & $18(0.4)$ & $0.04(-0.19-0.27)$ & 0.73 \\
\hline Urinary Tract Infection & $109(2.2)$ & $80(1.6)$ & $-0.58(-1.12--0.04)$ & 0.034 \\
\hline Sepsis & $11(0.2)$ & $18(0.4)$ & $0.14(-0.07-0.35)$ & 0.19 \\
\hline \multicolumn{5}{|l|}{ Local complications } \\
\hline Hip dislocation & $24(0.5)$ & $160(3.2)$ & $2.74(2.21-3.27)$ & $<0.001$ \\
\hline Surgical site infection & $47(0.9)$ & $74(1.5)$ & $0.54(0.11-0.98)$ & 0.014 \\
\hline Secondary revision surgery & $30(0.6)$ & $170(3.4)$ & $2.82(2.27-3.37)$ & $<0.001$ \\
\hline
\end{tabular}

Table 3. Thirty-day mortality and other clinical outcomes between propensity score matched group.

\begin{tabular}{|c|c|c|c|c|}
\hline & Hazard Ratio $(95 \%$ CI) & $p$-Value & & \\
\hline \multirow[t]{2}{*}{ Secondary revision surgery } & $6.68(4.27-10.46)$ & $<0.001$ & \multirow[b]{2}{*}{$\begin{array}{l}\text { Absolute risk difference } \\
(95 \% \mathrm{CI}), \%\end{array}$} & \multirow[b]{2}{*}{$p$-value } \\
\hline & $N(\%)$ & $N(\%)$ & & \\
\hline 30-day Hospital Death & $30(0.6)$ & $34(0.7)$ & $0.08(-0.24-0.4)$ & 0.62 \\
\hline Intensive Care Unit (ICU) admission & $115(2.3)$ & $171(3.4)$ & $1.13(0.47-1.79)$ & $<0.001$ \\
\hline \multirow[t]{2}{*}{ Blood Transfusion } & $434(8.7)$ & $774(15.6)$ & $6.85(5.58-8.11)$ & $<0.001$ \\
\hline & $\begin{array}{l}\text { Mean (Standard } \\
\text { Deviation(SD)) }\end{array}$ & Mean (SD) & $\begin{array}{l}\text { Absolute mean difference } \\
(95 \% \mathrm{CI}), \%\end{array}$ & $p$-value \\
\hline Anesthesia time, minute & $110.31(45.31)$ & $146.92(64.40)$ & $36.61(34.44-38.78)$ & $<0.001$ \\
\hline Length of hospital stay, day & $35.93(22.98)$ & $38.88(27.40)$ & $2.96(1.96-3.95)$ & $<0.001$ \\
\hline Daily average medical cost, USD & $58.98(21.24)$ & $66.69(25.28)$ & $-7.71(6.79-8.64)$ & $<0.001$ \\
\hline
\end{tabular}


Any systemic complication was observed in $10.0 \%$ of patients in the HA group, whereas the prevalence of systemic complication was $9.1 \%$ in the THA group; there was no significant difference between the two groups (RD, $-0.26 ; 95 \% \mathrm{CI},-1.39-0.86 ; p=0.65)$. However, blood transfusion and Intensive Care Unit (ICU) admission after surgery was more often found in the THA group than in the HA group (RD, 6.85; RD, 1.13; both $p<0.001$ ).

Any local complication was observed in $2.3 \%$ of patients in the HA group, as opposed to $6.2 \%$ of patients in the THA group (RD, 3.83; 95\%CI, 3.04-4.61; $p<0.001$ ). The incidence of hip dislocation, surgical site infection, debridement, and revision surgery were significantly higher in THA group compared to the HA group (RD, 2.74; RD, 0.54; RD, 0.99; RD, 2.82, respectively, all $p<0.002$ ). THA was significantly associated with revision surgery during hospital stay, compared to hemiarthroplasty (Hazard Ratio, 6.68; 95\% confidence interval, 4.27-10.46; $p<0.001$; Figure 1). THA required longer anesthesia time (RD, 37.17 minutes; 95\%CI, 34.99-39.35; $p<0.001$ ) than HA. The daily average medical cost was significantly higher in the THA group than in the HA group before and after matching (RD, 7.71 dollars; 95\%CI, 6.79-8.63; $p<0.001$ ). The result of the sensitivity analysis shows a similar association between surgical procedure, such as THA or HA, and complications (Table A4).

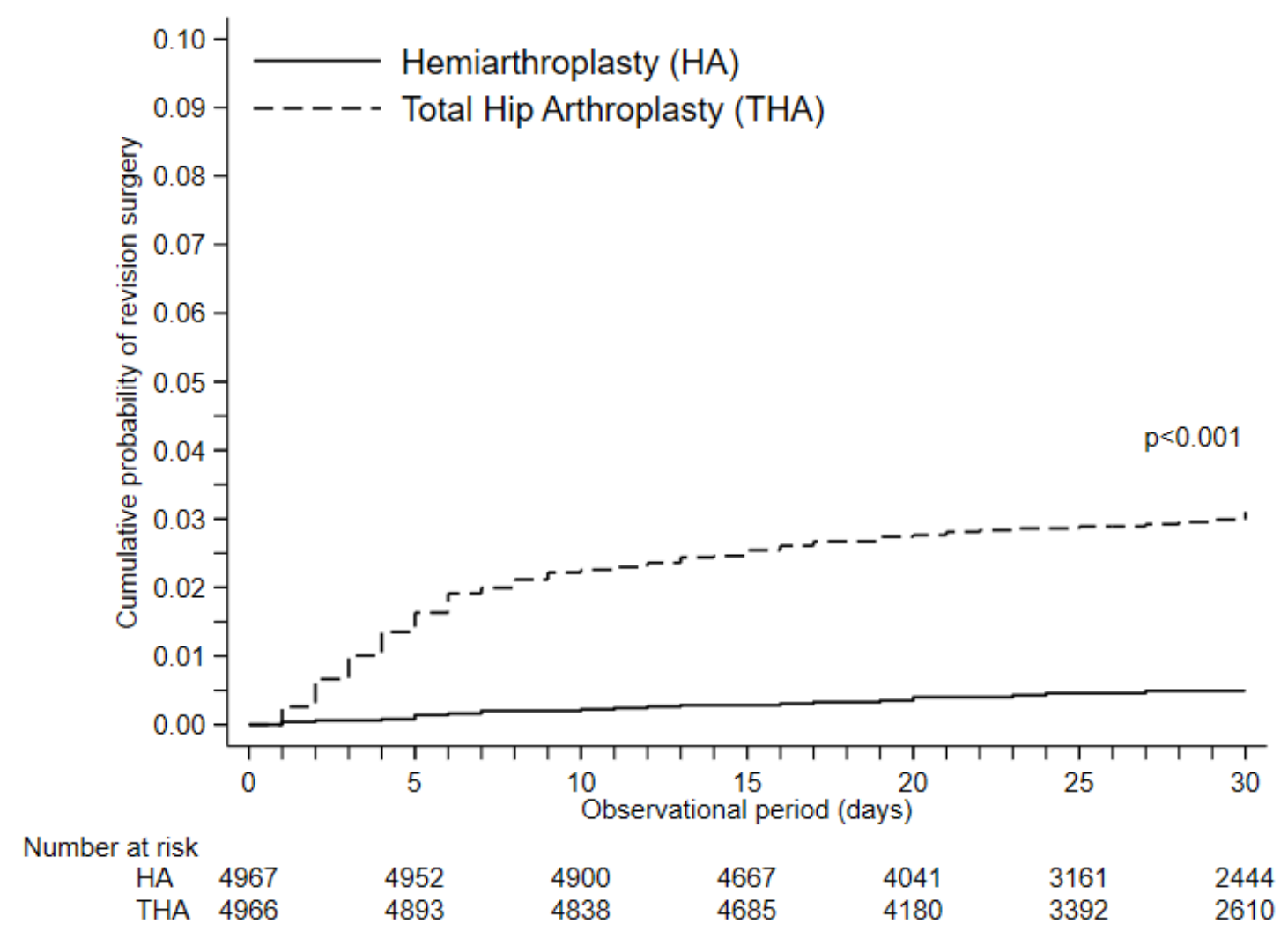

Figure 1. Kaplan-Meier curve of secondary revision surgery. The $p$-value of the log-lank test was $<0.001$.

\section{Discussion}

The present study showed that the incidence of local complications in surgically treated femoral neck fractures were significantly higher among THA group compared to the HA group after propensity score matching $(\mathrm{RD}, 3.83 ; p<0.001)$. The overall systemic complication rate was $9.2 \%$, and mortality was $0.6 \%$. Neither the systemic complication rate nor the mortality rate differed between the two groups when comparing HA and THA, which is consistent with the findings of previous studies $[7,8,26,27]$.

The THA group showed a higher incidence of local complications including surgical site infection, debridement, and revision after surgery than the HA group. Dislocation is the major concern after both HA and THA for displaced femoral neck fractures in elderly patients. Previous studies have 
shown that the postoperative dislocation rate is higher in THA than in HA [28,29], whereas other studies have indicated no increase in the complication rate, including dislocation rate, after THA $[6,7]$. Our results showed that the risk of hip dislocation during the postoperative in-hospital period was significantly higher in the THA group than in the HA group dislocation (RD, 2.74\%; 95\%CI, 2.21-3.27; $p<0.001$ ) which we supposed to be the main cause of the higher risk of revision surgery in the THA group (RD, 2.82; 95\%CI, 2.27-3.37; $p<0.001$ ). The reason for this higher risk of dislocation with THA may be the smaller size of the head of the femoral implant in THA than in HA. Previous studies have demonstrated that the size of the femoral head affects the incidence of dislocation after surgery [30-32]. Another potential reason for this higher risk of dislocation with THA is that a large preoperative range of motion and soft tissue damage due to trauma may contribute to high risk of dislocation [33-36]. Hip dislocation within five weeks after the surgery, especially, is a risk factor of revision surgery compared to delayed dislocation [37]. Extensive care should be taken to prevent dislocation during hospitalization after THA in elderly patients with femoral neck fracture.

The results of this study show longer anesthesia time and higher rate of blood transfusion with THA than with HA, suggesting greater surgical extensiveness and complicated procedures of THA for elderly patients, which is consistent with previous studies $[1,6,8,15,38]$. Longer surgical time and blood transfusion are also associated with surgical site complication or following a debridement procedure [39-42]. These complications could also be attributed to the higher incidence of revision surgery in addition to hip dislocation.

The results of our study showed that daily average medical costs for hospitalization were significantly higher in the THA group compared to the HA group. Although systemic complication rates were similar in the two groups in this study, the expense of THA was higher in the early period after surgery, possibly because of additional implants (i.e., acetabular component) and additional blood transfusion, as previously reported $[1,43]$. Furthermore, the higher incidence of dislocation and subsequent reoperation may have contributed to the higher medical costs in the THA group. Nonetheless, the Quality of Life (QOL) of patients is reported to be better after THA than after HA, and the difference becomes increasingly marked over time [6,7]. Therefore, the cost-effectiveness of the THA procedure may become more favorable after long-term follow-up.

The present study has some limitations. First, the national database did not include detailed information about surgical procedures or implants. Therefore, several important factors regarding dislocation, such as type of surgical approach and type and size of the implant, and angle of implant placement were not evaluated. Second, information about each surgeon's skills, experience, and operating time was not available. Surgical skills are known to be associated with fewer complications $[20,44,45]$. However, we included hospital procedure volume in the statistical model to consider the confounding effect of the surgeon's skills. In addition, the similar result of our sensitivity analysis supports the robustness of our research. We used hospital procedure volume as a proxy, as experienced hip expertise surgeons are likely allocated to large-volume hospitals. Third, we matched various factors, including pre- and perioperative comorbidities and ADL scores, among others. However, the degree of these comorbidities and functional hip score could not be obtained and were not matched. These factors can be residual confounding factors even after propensity score matching.

\section{Conclusions}

Compared to HA in elderly patients with femoral neck fracture, THA was associated with a higher incidence of local complications and reoperation. Surgeons should consider the merits and demerits of both procedures when deciding on the surgical method for treating femoral neck fracture in elderly patients.

\section{Patents}

None. 
Author Contributions: Conceptualization, T.O. and T.Y.; Investigation, T.O., M.M., K.F., and T.F.; Supervision, T.Y., K.S., and A.O.; Writing—original draft, T.O.; Writing—review and editing, A.N., K.M., Y.O., and S.M. All authors have read and agreed to the published version of the manuscript.

Funding: This investigation received no external funding.

Conflicts of Interest: The authors declare no conflict of interest. All authors have read and agreed to the published version of the manuscript.

\section{Appendix A}

Table A1. International Classification of Diseases (ICD)-10 definitions for comorbidities and complications.

\begin{tabular}{ll}
\hline \multicolumn{1}{c}{ Comorbidities } & \multicolumn{1}{c}{ ICD-10 Codes } \\
\hline myocardial infarction & I21, I22, I252 \\
heart failure & I50 \\
peripheral vascular disease & I71, I790, I739, R02, Z958, Z959 \\
cerebrovascular disease & I60-63, I65-66, G450-452, G458-459, G46, I64, G454, I670-672, I674, I675-679, \\
dementia & I681-682, I688, I69 \\
pulmonary disease & F00-03, F051, G30 \\
connective tissue disease & M32, M60-67 \\
gastric ulcer & K25-28 \\
mild liver disease & K702-703, K73, K717, K740, K742-746 \\
diabetes mellitus & E109, E119, E139, E149, E101, E111, E131, E141, E105, E115, E135, E145 \\
diabetes with complications & E102, E112, E132, E142, E142, E113, E133, E143, E104, E114, E117, E134, E144, \\
paralysis & E117 \\
renal failure & G041, G820, G821, G822 \\
cancer & N03, N052-056, N072-074, N01, N18-19, N25 \\
metastatic cancer & C0-9 \\
severe liver disease & C77-80 \\
HIV & K729, K766-7, K721 \\
anemia & B20-24 \\
hypertension & D509 \\
osteoarthritis of hip & I10 \\
\hline Complications & M16 \\
\hline surgical site infection & ICD-10 codes \\
Debridement & T793, T814 \\
\hline
\end{tabular}

Table A2. ICD-10 definitions for complications.

\begin{tabular}{ll}
\hline Complications & ICD-10 Codes \\
\hline surgical site infection & T793, T814 \\
acute coronary syndrome & $\mathrm{I} 20-25$ \\
heart failure & $\mathrm{I} 50$ \\
respiratory disorder & $\mathrm{J} 12-18, \mathrm{~J} 95-96$ \\
sepsis & $\mathrm{A} 40-41, \mathrm{D} 65$ \\
pulmonary embolism & $\mathrm{I} 26$ \\
cerebrovascular disease & $\mathrm{I} 60-64$ \\
renal failure & $\mathrm{N} 17-19$ \\
urinary tract infection & $\mathrm{N} 390$ \\
Hip dislocation & $\mathrm{K} 0631$ \\
\hline
\end{tabular}


Table A3. Patient characteristics (Full description).

\begin{tabular}{|c|c|c|c|c|c|c|}
\hline & \multicolumn{3}{|c|}{ Before Matching } & \multicolumn{3}{|c|}{ After Matching } \\
\hline & Hemiarthroplasty & $\begin{array}{l}\text { Total Hip } \\
\text { Arthroplasty }\end{array}$ & SMD & Hemiarthroplasty & $\begin{array}{l}\text { Total Hip } \\
\text { Arthroplasty }\end{array}$ & SMD \\
\hline & $N=281,140$ & $N=5129$ & $\%$ & $N=4967$ & $N=4967$ & $\%$ \\
\hline Age & $81.80(8.32)$ & $73.63(8.72)$ & 95.9 & $74.53(8.95)$ & $73.69(8.74)$ & 9.5 \\
\hline \multicolumn{7}{|l|}{ Age } \\
\hline $60-$ & $27,334(9.7)$ & 2048 (39.9) & 74.6 & $1954(39.3)$ & 1965 (39.6) & 0.5 \\
\hline 70- & $71,128(25.3)$ & $1693(33.0)$ & 17 & $1585(31.9)$ & $1646(33.1)$ & 2.6 \\
\hline $80-$ & $133,167(47.4)$ & $1169(22.8)$ & 53.3 & $1175(23.7)$ & $1140(23.0)$ & 1.7 \\
\hline $90-$ & $48,261(17.2)$ & $217(4.2)$ & 42.8 & $250(5.0)$ & $214(4.3)$ & 3.4 \\
\hline $100-$ & $1250(0.4)$ & $2(0.0)$ & 8.3 & $3(0.1)$ & $2(0.0)$ & 0.9 \\
\hline Female & $219,042(77.9)$ & $3951(77.0)$ & 2.1 & $3829(77.1)$ & $3826(77.0)$ & 0.1 \\
\hline \multicolumn{7}{|l|}{ BMI } \\
\hline$<18.5$ & $75,851(27.0)$ & 1055 (20.6) & 15.1 & 1068 (21.5) & $1032(20.8)$ & 1.8 \\
\hline $18.5-25$ & $157,959(56.2)$ & 2994 (58.4) & 4.4 & $2872(57.8)$ & $2893(58.2)$ & 0.9 \\
\hline $25-30$ & $23,574(8.4)$ & $679(13.2)$ & 15.7 & $623(12.5)$ & $650(13.1)$ & 1.6 \\
\hline$\geq 30$ & $2953(1.1)$ & $101(2.0)$ & 7.5 & $94(1.9)$ & $96(1.9)$ & 0.3 \\
\hline Missing & 20,803 (7.4) & $300(5.8)$ & 6.2 & $310(6.2)$ & $296(6.0)$ & 1.2 \\
\hline \multicolumn{7}{|l|}{ Smoking } \\
\hline Never-smoking & $225,634(80.3)$ & $3847(75.0)$ & 12.6 & $3726(75.0)$ & $3711(74.7)$ & 0.7 \\
\hline Smoking & $31,669(11.3)$ & $774(15.1)$ & 11.3 & $762(15.3)$ & $758(15.3)$ & 0.2 \\
\hline Missing & $23,837(8.5)$ & $508(9.9)$ & 4.9 & $479(9.6)$ & $498(10.0)$ & 1.3 \\
\hline Hip Osteoarthritis & $390(0.1)$ & $346(6.7)$ & 36.8 & $235(4.7)$ & $194(3.9)$ & 4.1 \\
\hline Coronary heart disease & $3785(1.3)$ & $53(1.0)$ & 2.9 & $50(1.0)$ & $50(1.0)$ & 0 \\
\hline Heart failure & $19,996(7.1)$ & $211(4.1)$ & 13.1 & $216(4.3)$ & $205(4.1)$ & 1.1 \\
\hline Peripheral vascular disease & $1384(0.5)$ & $20(0.4)$ & 1.5 & $17(0.3)$ & $19(0.4)$ & 0.7 \\
\hline Stroke & $29,152(10.4)$ & $305(5.9)$ & 16.2 & $316(6.4)$ & $301(6.1)$ & 1.3 \\
\hline Dementia & $46,326(16.5)$ & $363(7.1)$ & 29.5 & $430(8.7)$ & $359(7.2)$ & 5.3 \\
\hline Pulmonary Disorders & $10,761(3.8)$ & $140(2.7)$ & 6.2 & $116(2.3)$ & $135(2.7)$ & 2.4 \\
\hline Connective tissue disease & $725(0.3)$ & $27(0.5)$ & 4.3 & $38(0.8)$ & $27(0.5)$ & 2.7 \\
\hline Peptic ulcer & $8509(3.0)$ & $164(3.2)$ & 1 & $153(3.1)$ & $160(3.2)$ & 0.8 \\
\hline Mild liver disease & $1522(0.5)$ & $19(0.4)$ & 2.5 & $22(0.4)$ & $19(0.4)$ & 0.9 \\
\hline Mild to moderate diabetes & $42,034(15.0)$ & $784(15.3)$ & 0.9 & $774(15.6)$ & $764(15.4)$ & 0.6 \\
\hline $\begin{array}{l}\text { Diabetes with } \\
\text { complications }\end{array}$ & $7337(2.6)$ & $135(2.6)$ & 0.1 & $122(2.5)$ & $134(2.7)$ & 1.5 \\
\hline Hemiplegia & $18(0.0)$ & $0(0.0)$ & 1.1 & $0(0.0)$ & $0(0.0)$ & 0 \\
\hline Renal failure & $13,073(4.6)$ & $196(3.8)$ & 4.1 & $210(4.2)$ & $194(3.9)$ & 1.6 \\
\hline Cancer & $13,742(4.9)$ & $211(4.1)$ & 3.7 & 235 (4.7) & $206(4.1)$ & 2.8 \\
\hline Metastatic cancer & $1307(0.5)$ & $13(0.3)$ & 3.5 & $14(0.3)$ & $13(0.3)$ & 0.4 \\
\hline Sever liver disease & $54(0.0)$ & $0(0.0)$ & 2 & $0(0.0)$ & $0(0.0)$ & 0 \\
\hline HIV & $21(0.0)$ & $1(0.0)$ & 1 & $0(0.0)$ & $1(0.0)$ & 2 \\
\hline Hypertension & $97,910(34.8)$ & $1525(29.7)$ & 10.9 & $1420(28.6)$ & $1489(30.0)$ & 3.1 \\
\hline Stable angina & $19,813(7.0)$ & $276(5.4)$ & 6.9 & $259(5.2)$ & $271(5.5)$ & 1.1 \\
\hline Parkinson disease & $8036(2.9)$ & $128(2.5)$ & 2.2 & $132(2.7)$ & $126(2.5)$ & 0.8 \\
\hline Anemia & $8069(2.9)$ & $223(4.3)$ & 7.9 & $186(3.7)$ & $212(4.3)$ & 2.7 \\
\hline \multicolumn{7}{|l|}{ Feeding } \\
\hline 0 & $79,240(28.2)$ & $881(17.2)$ & 26.5 & $893(18.0)$ & $862(17.4)$ & 1.6 \\
\hline 5 & $115,601(41.1)$ & $1862(36.3)$ & 9.9 & $1794(36.1)$ & $1810(36.4)$ & 0.7 \\
\hline 10 & $77,322(27.5)$ & $2269(44.2)$ & 35.4 & $2176(43.8)$ & 2178 (43.8) & 0.1 \\
\hline Missing & $8977(3.2)$ & $117(2.3)$ & 5.6 & $104(2.1)$ & $117(2.4)$ & 1.8 \\
\hline \multicolumn{7}{|l|}{ Chair/bed transfers } \\
\hline 0 & $201,968(71.8)$ & $2976(58.0)$ & 29.3 & $2820(56.8)$ & $2908(58.5)$ & 3.6 \\
\hline 5 & $24,036(8.5)$ & $451(8.8)$ & 0.9 & $461(9.3)$ & $438(8.8)$ & 1.6 \\
\hline 10 & $23,615(8.4)$ & $719(14.0)$ & 17.9 & $708(14.3)$ & $683(13.8)$ & 1.5 \\
\hline 15 & $21,656(7.7)$ & $819(16.0)$ & 25.8 & $833(16.8)$ & $777(15.6)$ & 3.1 \\
\hline Missing & $9865(3.5)$ & $164(3.2)$ & 1.7 & $145(2.9)$ & $161(3.2)$ & 1.9 \\
\hline \multicolumn{7}{|l|}{ Personal hygiene } \\
\hline 0 & 230,491 (82.0) & 3505 (68.3) & 32 & 3392 (68.3) & 3417 (68.8) & 1.1 \\
\hline 5 & $41,256(14.7)$ & $1498(29.2)$ & 35.7 & $1471(29.6)$ & $1427(28.7)$ & 1.9 \\
\hline Missing & $9393(3.3)$ & $126(2.5)$ & 5.3 & $104(2.1)$ & $123(2.5)$ & 2.6 \\
\hline
\end{tabular}


Table A3. Cont.

\begin{tabular}{|c|c|c|c|c|c|c|}
\hline & \multicolumn{3}{|c|}{ Before Matching } & \multicolumn{3}{|c|}{ After Matching } \\
\hline & Hemiarthroplasty & $\begin{array}{l}\text { Total Hip } \\
\text { Arthroplasty }\end{array}$ & SMD & Hemiarthroplasty & $\begin{array}{l}\text { Total Hip } \\
\text { Arthroplasty }\end{array}$ & SMD \\
\hline \multicolumn{7}{|l|}{ Toilet } \\
\hline 0 & 220,017 (78.3) & 3,213 (62.6) & 34.7 & $3070(61.8)$ & 3141 (63.2) & 3 \\
\hline 5 & 29,787 (10.6) & $880(17.2)$ & 19.1 & $883(17.8)$ & $838(16.9)$ & 2.4 \\
\hline 10 & $22,752(8.1)$ & 907 (17.7) & 28.9 & $905(18.2)$ & 859 (17.3) & 2.4 \\
\hline Missing & $8584(3.1)$ & $129(2.5)$ & 3.3 & $109(2.2)$ & $129(2.6)$ & 2.6 \\
\hline \multicolumn{7}{|l|}{ Bathing self } \\
\hline 0 & $231,390(82.3)$ & $3780(73.7)$ & 20.9 & $3623(72.9)$ & $3682(74.1)$ & 2.7 \\
\hline 5 & $19,402(6.9)$ & 787 (15.3) & 27.1 & $785(15.8)$ & $745(15.0)$ & 2.2 \\
\hline Missing & $30,348(10.8)$ & $562(11.0)$ & 0.5 & $559(11.3)$ & $540(10.9)$ & 1.2 \\
\hline \multicolumn{7}{|l|}{ Ambulation } \\
\hline 0 & 216,824 (77.1) & $3437(67.0)$ & 22.7 & $3303(66.5)$ & $3348(67.4)$ & 1.9 \\
\hline 5 & $8293(2.9)$ & $296(5.8)$ & 13.8 & $314(6.3)$ & $284(5.7)$ & 2.5 \\
\hline 10 & $9337(3.3)$ & $245(4.8)$ & 7.4 & $226(4.6)$ & $236(4.8)$ & 1 \\
\hline 15 & $19,314(6.9)$ & $723(14.1)$ & 23.8 & $738(14.9)$ & $687(13.8)$ & 2.9 \\
\hline Missing & $27,372(9.7)$ & $428(8.3)$ & 4.9 & $386(7.8)$ & $412(8.3)$ & 1.9 \\
\hline \multicolumn{7}{|l|}{ Stair climbing } \\
\hline 0 & $218,388(77.7)$ & $3583(69.9)$ & 17.9 & 3464 (69.7) & 3489 (70.2) & 1.1 \\
\hline 5 & $10,304(3.7)$ & $284(5.5)$ & 8.9 & $272(5.5)$ & $275(5.5)$ & 0.3 \\
\hline 10 & $17,565(6.2)$ & $665(13.0)$ & 22.9 & $693(14.0)$ & $635(12.8)$ & 3.4 \\
\hline Missing & $34,883(12.4)$ & 597 (11.6) & 2.4 & $538(10.8)$ & $568(11.4)$ & 1.9 \\
\hline \multicolumn{7}{|l|}{ Dressing } \\
\hline 0 & $213,137(75.8)$ & $3023(58.9)$ & 36.6 & 2905 (58.5) & 2959 (59.6) & 2.2 \\
\hline 5 & $39,876(14.2)$ & $1151(22.4)$ & 21.5 & $1134(22.8)$ & $1101(22.2)$ & 1.6 \\
\hline 10 & $21,980(7.8)$ & $858(16.7)$ & 27.4 & $850(17.1)$ & $814(16.4)$ & 1.9 \\
\hline Missing & $6147(2.2)$ & $97(1.9)$ & 2.1 & $78(1.6)$ & $93(1.9)$ & 2.3 \\
\hline \multicolumn{7}{|l|}{ Bladder control } \\
\hline 0 & $179,341(63.8)$ & $2361(46.0)$ & 36.3 & $2337(47.1)$ & 2317 (46.6) & 0.8 \\
\hline 5 & $31,870(11.3)$ & 649 (12.7) & 4.1 & $643(12.9)$ & $627(12.6)$ & 1 \\
\hline 10 & $56,123(20.0)$ & $1890(36.8)$ & 38.1 & $1792(36.1)$ & $1801(36.3)$ & 0.4 \\
\hline Missing & $13,806(4.9)$ & $229(4.5)$ & 2.1 & $195(3.9)$ & $222(4.5)$ & 2.7 \\
\hline \multicolumn{7}{|l|}{ Bowel control } \\
\hline 0 & $182,952(65.1)$ & $2444(47.7)$ & 35.7 & $2395(48.2)$ & $2398(48.3)$ & 0.1 \\
\hline 5 & $31,251(11.1)$ & $622(12.1)$ & 3.2 & $614(12.4)$ & $601(12.1)$ & 0.8 \\
\hline 10 & $53,424(19.0)$ & $1831(35.7)$ & 38.1 & 1755 (35.3) & $1744(35.1)$ & 0.5 \\
\hline Missing & $13,513(4.8)$ & $232(4.5)$ & 1.3 & $203(4.1)$ & $224(4.5)$ & 2.1 \\
\hline \multicolumn{7}{|l|}{ Wait time for surgery } \\
\hline Less than 72 hours & $138,190(49.2)$ & $1723(33.6)$ & 32 & $1721(34.6)$ & $1681(33.8)$ & 1.7 \\
\hline More than 72 hours & $142,950(50.8)$ & $3406(66.4)$ & 32 & $3246(65.4)$ & $3286(66.2)$ & 1.7 \\
\hline \multicolumn{7}{|l|}{ Anesthesia } \\
\hline General Anesthesia & $158,846(56.5)$ & 3595 (70.1) & 28.5 & 3352 (67.5) & 3504 (70.5) & 6.6 \\
\hline Spinal Anesthesia & $111,120(39.5)$ & $533(10.4)$ & 71.5 & $660(13.3)$ & $532(10.7)$ & 7.9 \\
\hline General and Epidural & $9975(3.5)$ & $963(18.8)$ & 49.8 & $916(18.4)$ & $893(18.0)$ & 1.2 \\
\hline Spinal and Epidural & $1199(0.4)$ & $38(0.7)$ & 4.1 & $39(0.8)$ & $38(0.8)$ & 0.2 \\
\hline Teaching Hospitals & $8003(2.8)$ & $529(10.3)$ & 30.5 & $582(11.7)$ & $504(10.1)$ & 5 \\
\hline \multicolumn{7}{|l|}{ Hospital Volume, bed } \\
\hline$<100$ & $49,585(17.6)$ & $599(11.7)$ & 16.9 & $612(12.3)$ & $583(11.7)$ & 1.8 \\
\hline $100-200$ & $87,074(31.0)$ & $1437(28.0)$ & 6.5 & $1321(26.6)$ & $1388(27.9)$ & 3 \\
\hline $200-300$ & $65,345(23.2)$ & 1177 (22.9) & 0.7 & $1135(22.9)$ & $1145(23.1)$ & 0.5 \\
\hline $300-400$ & $35,514(12.6)$ & $644(12.6)$ & 0.2 & $622(12.5)$ & $623(12.5)$ & 0.1 \\
\hline $400-500$ & $20,552(7.3)$ & $523(10.2)$ & 10.2 & $516(10.4)$ & $509(10.2)$ & 0.5 \\
\hline$>500$ & $23,070(8.2)$ & 749 (14.6) & 20.2 & $761(15.3)$ & $719(14.5)$ & 2.4 \\
\hline \multicolumn{7}{|l|}{ Annual Procedure Volume } \\
\hline$\sim 30$ case/year & $19,504(6.9)$ & $506(9.9)$ & 10.6 & $582(11.7)$ & $488(9.8)$ & 6.1 \\
\hline 30 100 case/year & $123,221(43.8)$ & $2377(46.3)$ & 5.1 & 2259 (45.5) & $2302(46.3)$ & 1.7 \\
\hline 100 case/year & 138,415 (49.2) & $2246(43.8)$ & 10.9 & $2126(42.8)$ & 2177 (43.8) & 2.1 \\
\hline
\end{tabular}


Table A3. Cont.

\begin{tabular}{|c|c|c|c|c|c|c|}
\hline & \multicolumn{3}{|c|}{ Before Matching } & \multicolumn{3}{|c|}{ After Matching } \\
\hline & Hemiarthroplasty & $\begin{array}{l}\text { Total Hip } \\
\text { Arthroplasty }\end{array}$ & SMD & Hemiarthroplasty & $\begin{array}{l}\text { Total Hip } \\
\text { Arthroplasty }\end{array}$ & SMD \\
\hline \multicolumn{7}{|l|}{ Year } \\
\hline 2010 & $18,673(6.6)$ & $154(3.0)$ & 17 & $160(3.2)$ & $152(3.1)$ & 0.9 \\
\hline 2011 & $19,917(7.1)$ & $192(3.7)$ & 14.8 & $192(3.9)$ & $187(3.8)$ & 0.5 \\
\hline 2012 & $26,786(9.5)$ & $279(5.4)$ & 15.6 & $270(5.4)$ & $272(5.5)$ & 0.2 \\
\hline 2013 & $28,549(10.2)$ & $364(7.1)$ & 10.9 & $373(7.5)$ & $352(7.1)$ & 1.6 \\
\hline 2014 & $37,737(13.4)$ & $544(10.6)$ & 8.7 & $494(9.9)$ & $523(10.5)$ & 1.9 \\
\hline 2015 & $38,091(13.5)$ & $674(13.1)$ & 1.2 & $648(13.0)$ & $661(13.3)$ & 0.8 \\
\hline 2016 & $39,869(14.2)$ & $842(16.4)$ & 6.2 & $832(16.8)$ & $821(16.5)$ & 0.6 \\
\hline 2017 & $38,810(13.8)$ & $964(18.8)$ & 13.5 & $885(17.8)$ & $931(18.7)$ & 2.4 \\
\hline 2018 & 32,708 (11.6) & $1116(21.8)$ & 27.4 & $1113(22.4)$ & $1068(21.5)$ & 2.2 \\
\hline \multicolumn{7}{|l|}{ Season } \\
\hline Spring & $64,476(22.9)$ & $1219(23.8)$ & 2 & $1194(24.0)$ & 1178 (23.7) & 0.8 \\
\hline Summer & $64,527(23.0)$ & $1111(21.7)$ & 3.1 & $1086(21.9)$ & $1078(21.7)$ & 0.4 \\
\hline Fall & $77,139(27.4)$ & $1408(27.5)$ & 0 & $1328(26.7)$ & $1368(27.5)$ & 1.8 \\
\hline Winter & $74,998(26.7)$ & $1391(27.1)$ & 1 & $1359(27.4)$ & $1343(27.0)$ & 0.7 \\
\hline \multicolumn{7}{|c|}{ Admission day of the week } \\
\hline Sunday & $26,262(9.3)$ & $502(9.8)$ & 1.5 & $491(9.9)$ & $489(9.8)$ & 0.1 \\
\hline Monday & $49,885(17.7)$ & 939 (18.3) & 1.5 & $878(17.7)$ & $914(18.4)$ & 1.9 \\
\hline Tuesday & $45,088(16.0)$ & $812(15.8)$ & 0.6 & $802(16.1)$ & $786(15.8)$ & 0.9 \\
\hline Wednesday & $42,041(15.0)$ & $825(16.1)$ & 3.1 & $787(15.8)$ & $796(16.0)$ & 0.5 \\
\hline Thursday & $41,598(14.8)$ & $720(14.0)$ & 2.2 & $736(14.8)$ & $702(14.1)$ & 1.9 \\
\hline Friday & $43,975(15.6)$ & $780(15.2)$ & 1.2 & $757(15.2)$ & $753(15.2)$ & 0.2 \\
\hline Saturday & 32,291 (11.5) & 551 (10.7) & 2.4 & $516(10.4)$ & 527 (10.6) & 0.7 \\
\hline
\end{tabular}

The values are given as the number of patients, with the percentage of the cohort in parentheses, with the exception of age, and Barthel Index, which are given as the mean and standard deviation. BMI, body mass index; HIV, human immunodeficiency virus; $N$, number of patients; SMD, standardized mean difference.

Table A4. Sensitivity analysis (Stabilized Inverse Probability Weighting).

\begin{tabular}{|c|c|c|}
\hline & $\begin{array}{c}\text { Absolute Risk Difference (95\% Confidence } \\
\text { Interval(CI)), } \% a\end{array}$ & $p$-Value \\
\hline In-Hospital death & $0.07(-0.86-0.99)$ & 0.89 \\
\hline Systemic complication & $-0.02(-2.17-2.12)$ & $<0.001$ \\
\hline Coronary Heart Disease & $-0.81(-1.2--0.42)$ & $<0.001$ \\
\hline Heart Failure & $0.35(-0.71-1.41)$ & 0.51 \\
\hline Respiratory Disorders & $-0.47(-1.28-0.34)$ & 0.25 \\
\hline Pulmonary Embolism & $-0.07(-0.32-0.17)$ & 0.55 \\
\hline Stroke & $-0.3(-0.6-0)$ & 0.048 \\
\hline Renal Failure & $0.11(-0.43-0.64)$ & 0.7 \\
\hline Urinary Tract Infection & $-0.99(-1.61--0.37)$ & 0.002 \\
\hline Sepsis & $-0.14(-0.37-0.09)$ & 0.25 \\
\hline Intensive Care Unit (ICU) admission & $1.91(0.43-3.39)$ & 0.012 \\
\hline Blood Transfusion & $9.25(5.62-12.88)$ & $<0.001$ \\
\hline Local complications & $4.16(2.48-5.83)$ & $<0.001$ \\
\hline Secondary revision surgery & $4.4(2.58-6.22)$ & $<0.001$ \\
\hline Hip dislocation & $3.58(2.06-5.11)$ & $<0.001$ \\
\hline Surgical site infection & $0.33(-0.23-0.89)$ & 0.25 \\
\hline \multirow[t]{2}{*}{ Debridement } & $0.42(-0.07-0.92)$ & 0.09 \\
\hline & Absolute risk difference $(95 \% \mathrm{CI}), \%$ a & $p$-value \\
\hline Anesthesia time & 37.821 & $<0.001$ \\
\hline Length of hospital stay & 6.928 & 0.001 \\
\hline
\end{tabular}




\section{References}

1. Ju, D.G.; Rajaee, S.S.; Mirocha, J.; Lin, C.A.; Moon, C.N. Nationwide Analysis of Femoral Neck Fractures in Elderly Patients: A Receding Tide. J. Bone Jt. Surg. Am. Vol. 2017, 99, 1932-1940. [CrossRef] [PubMed]

2. Roberts, K.C.; Brox, W.T.; Jevsevar, D.S.; Sevarino, K. Management of Hip Fractures in the Elderly. J. Am. Acad. Orthop. Surg. 2015, 23, 131-137. [CrossRef] [PubMed]

3. Avery, P.P.; Baker, R.P.; Walton, M.J.; Rooker, J.C.; Squires, B.; Gargan, M.F.; Bannister, G.C. Total hip replacement and hemiarthroplasty in mobile, independent patients with a displaced intracapsular fracture of the femoral neck: A seven-to ten-year follow-up report of a prospective randomised controlled trial. J. Bone Jt. Surg. Br. Vol. 2011, 93, 1045-1048. [CrossRef] [PubMed]

4. Baker, R.P.; Squires, B.; Gargan, M.F.; Bannister, G.C. Total hip arthroplasty and hemiarthroplasty in mobile, independent patients with a displaced intracapsular fracture of the femoral neck: A randomized, controlled trial. JBJS 2006, 88, 2583-2589. [CrossRef]

5. Barenius, B.; Inngul, C.; Alagic, Z.; Enocson, A. A randomized controlled trial of cemented versus cementless arthroplasty in patients with a displaced femoral neck fracture. Bone Jt. J. 2018, 100-b, 1087-1093. [CrossRef]

6. Blomfeldt, R.; Törnkvist, H.; Eriksson, K.; Söderqvist, A.; Ponzer, S.; Tidermark, J. A randomised controlled trial comparing bipolar hemiarthroplasty with total hip replacement for displaced intracapsular fractures of the femoral neck in elderly patients. J. Bone Jt. Surg. Br. Vol. 2007, 89, 160-165. [CrossRef]

7. Hedbeck, C.J.; Enocson, A.; Lapidus, G.; Blomfeldt, R.; Törnkvist, H.; Ponzer, S.; Tidermark, J. Comparison of bipolar hemiarthroplasty with total hip arthroplasty for displaced femoral neck fractures: A concise four-year follow-up of a randomized trial. JBJS 2011, 93, 445-450. [CrossRef]

8. Keating, J.F.; Grant, A.; Masson, M.; Scott, N.W.; Forbes, J.F. Randomized comparison of reduction and fixation, bipolar hemiarthroplasty, and total hip arthroplasty: Treatment of displaced intracapsular hip fractures in healthy older patients. JBJS 2006, 88, 249-260. [CrossRef]

9. Macaulay, W.; Nellans, K.W.; Iorio, R.; Garvin, K.L.; Healy, W.L.; Rosenwasser, M.P.; Consortium, D. Total hip arthroplasty is less painful at 12 months compared with hemiarthroplasty in treatment of displaced femoral neck fracture. HSS J. 2008, 4, 48-54. [CrossRef]

10. Zhao, Y.; Fu, D.; Chen, K.; Li, G.; Cai, Z.; Shi, Y.; Yin, X. Outcome of hemiarthroplasty and total hip replacement for active elderly patients with displaced femoral neck fractures: A meta-analysis of 8 randomized clinical trials. PLoS ONE 2014, 9, e98071. [CrossRef]

11. Cornwall, R.; Gilbert, M.S.; Koval, K.J.; Strauss, E.; Siu, A.L. Functional outcomes and mortality vary among different types of hip fractures: A function of patient characteristics. Clin. Orthop. Relat. Res. 2004, 425, 64-71. [CrossRef] [PubMed]

12. Holvik, K.; Ranhoff, A.H.; Martinsen, M.I.; Solheim, L.F. Predictors of mortality in older hip fracture inpatients admitted to an orthogeriatric unit in Oslo, Norway. J. Aging Health 2010, 22, 1114-1131. [CrossRef] [PubMed]

13. Kim, S.-Y.; Kim, Y.-G.; Hwang, J.-K. Cementless calcar-replacement hemiarthroplasty compared with intramedullary fixation of unstable intertrochanteric fractures: A prospective, randomized study. JBJS 2005, 87, 2186-2192. [CrossRef]

14. Talsnes, O.; Hjelmstedt, F.; Dahl, O.E.; Pripp, A.H.; Reikerås, O. Clinical and biochemical prediction of early fatal outcome following hip fracture in the elderly. Int. Orthop. 2011, 35, 903-907. [CrossRef] [PubMed]

15. Liodakis, E.; Antoniou, J.; Zukor, D.J.; Huk, O.L.; Epure, L.M.; Bergeron, S.G. Major Complications and Transfusion Rates After Hemiarthroplasty and Total Hip Arthroplasty for Femoral Neck Fractures. J. Arthroplast. 2016, 31, 2008-2012. [CrossRef]

16. Koval, K.J.; Rosenberg, A.D.; Zuckerman, J.D.; Aharonoff, G.B.; Skovron, M.L.; Bernstein, R.L.; Su, E.; Chakka, M. Does blood transfusion increase the risk of infection after hip fracture? J. Orthop. Trauma 1997, 11, 260-266. [CrossRef]

17. Ponnusamy, K.E.; Kim, T.J.; Khanuja, H.S. Perioperative Blood Transfusions in Orthopaedic Surgery. J. Bone Jt. Surg. Am. Vol. 2014, 96, 1836-1844. [CrossRef]

18. Brämer, G.R. International statistical classification of diseases and related health problems. Tenth revision. World Health Stat. Q 1988, 41, 32-36.

19. Yamana, H.; Moriwaki, M.; Horiguchi, H.; Kodan, M.; Fushimi, K.; Yasunaga, H. Validity of diagnoses, procedures, and laboratory data in Japanese administrative data. J. Epidemiol. 2017, 27, 476-482. [CrossRef] 
20. Katz, J.N.; Losina, E.; Barrett, J.; Phillips, C.B.; Mahomed, N.N.; Lew, R.A.; Guadagnoli, E.; Harris, W.H.; Poss, R.; Baron, J.A. Association Between Hospital and Surgeon Procedure Volume and Outcomes of Total Hip Replacement in the United States Medicare Population*. JBJS 2001, 83, 1622-1629. [CrossRef]

21. Quan, H.; Sundararajan, V.; Halfon, P.; Fong, A.; Burnand, B.; Luthi, J.-C.; Saunders, L.D.; Beck, C.A.; Feasby, T.E.; Ghali, W.A. Coding algorithms for defining comorbidities in ICD-9-CM and ICD-10 administrative data. Med. Care 2005, 43, 1130-1139. [CrossRef] [PubMed]

22. Mahoney, F.I.; Barthel, D.W. Functional evaluation: The Barthel Index: A simple index of independence useful in scoring improvement in the rehabilitation of the chronically ill. Md. State Med. J. 1965, 14, 61-65. [PubMed]

23. Rosenbaum, P.R.; Rubin, D.B. The central role of the propensity score in observational studies for causal effects. Biometrika 1983, 70, 41-55. [CrossRef]

24. Rubin, D.B. Using propensity scores to help design observational studies: Application to the tobacco litigation. Health Serv. Outcomes Res. Methodol. 2001, 2, 169-188. [CrossRef]

25. Austin, P.C. Balance diagnostics for comparing the distribution of baseline covariates between treatment groups in propensity-score matched samples. Stat. Med. 2009, 28, 3083-3107. [CrossRef]

26. Ravikumar, K.J.; Marsh, G. Internal fixation versus hemiarthroplasty versus total hip arthroplasty for displaced subcapital fractures of femur-13 year results of a prospective randomised study. Injury 2000, 31, 793-797. [CrossRef]

27. van den Bekerom, M.P.; Hilverdink, E.F.; Sierevelt, I.N.; Reuling, E.M.; Schnater, J.M.; Bonke, H.; Goslings, J.C.; van Dijk, C.N.; Raaymakers, E.L. A comparison of hemiarthroplasty with total hip replacement for displaced intracapsular fracture of the femoral neck: A randomised controlled multicentre trial in patients aged 70 years and over. J. Bone Jt. Surg Br. 2010, 92, 1422-1428. [CrossRef]

28. Investigators, H.; Bhandari, M.; Einhorn, T.A.; Guyatt, G.; Schemitsch, E.H.; Zura, R.D.; Sprague, S.; Frihagen, F.; Guerra-Farfan, E.; Kleinlugtenbelt, Y.V.; et al. Total Hip Arthroplasty or Hemiarthroplasty for Hip Fracture. N. Engl. J. Med. 2019, 381, 2199-2208. [CrossRef]

29. Poignard, A.; Bouhou, M.; Pidet, O.; Flouzat-Lachaniette, C.H.; Hernigou, P. High dislocation cumulative risk in THA versus hemiarthroplasty for fractures. Clin. Orthop. Relat. Res. 2011, 469, 3148-3153. [CrossRef]

30. Burroughs, B.R.; Hallstrom, B.; Golladay, G.J.; Hoeffel, D.; Harris, W.H. Range of motion and stability in total hip arthroplasty with 28-, 32-, 38-, and 44-mm femoral head sizes: An in vitro study. J. Arthroplast. 2005, 20, 11-19. [CrossRef]

31. Berry, D.J.; Von Knoch, M.; Schleck, C.D.; Harmsen, W.S. Effect of femoral head diameter and operative approach on risk of dislocation after primary total hip arthroplasty. JBJS 2005, 87, 2456-2463.

32. Woolson, S.T.; Rahimtoola, Z.O. Risk factors for dislocation during the first 3 months after primary total hip replacement. J. Arthroplast. 1999, 14, 662-668. [CrossRef]

33. Phillips, T.W. Thompson hemiarthroplasty and acetabular erosion. J. Bone Jt. Surg. Am. Vol. 1989, 71,913-917. [CrossRef]

34. Charnley, J. The long-term results of low-friction arthroplasty of the hip performed as a primary intervention. J. Bone Jt. Surg. Br. Vol. 1972, 54, 61-76. [CrossRef]

35. Gregory, R.J.; Gibson, M.J.; Moran, C.G. Dislocation after primary arthroplasty for subcapital fracture of the hip. Wide range of movement is a risk factor. J. Bone Jt. Surg. Br. Vol. 1991, 73, 11-12. [CrossRef]

36. Taine, W.H.; Armour, P.C. Primary total hip replacement for displaced subcapital fractures of the femur. J. Bone Jt. Surg. Br. Vol. 1985, 67, 214-217. [CrossRef]

37. Joshi, A.; Lee, C.; Markovic, L.; Vlatis, G.; Murphy, J. Prognosis of dislocation after total hip arthroplasty. J. Arthroplast. 1998, 13, 17-21. [CrossRef]

38. Swain, D.G.; Nightingale, P.G.; Patel, J.V. Blood transfusion requirements in femoral neck fracture. Injury 2000, 31, 7-10. [CrossRef]

39. Huotari, K.; Agthe, N.; Lyytikäinen, O. Validation of surgical site infection surveillance in orthopedic procedures. Am. J. Infect. Control. 2007, 35, 216-221. [CrossRef]

40. Ridgeway, S.; Wilson, J.; Charlet, A.; Kafatos, G.; Pearson, A.; Coello, R. Infection of the surgical site after arthroplasty of the hip. J. Bone Jt. Surg. Br. Vol. 2005, 87-B, 844-850. [CrossRef]

41. Kim, J.L.; Park, J.-H.; Han, S.-B.; Cho, I.Y.; Jang, K.-M. Allogeneic Blood Transfusion Is a Significant Risk Factor for Surgical-Site Infection Following Total Hip and Knee Arthroplasty: A Meta-Analysis. J. Arthroplast. 2017, 32, 320-325. [CrossRef] [PubMed] 
42. Frisch, N.B.; Wessell, N.M.; Charters, M.A.; Yu, S.; Jeffries, J.J.; Silverton, C.D. Predictors and Complications of Blood Transfusion in Total Hip and Knee Arthroplasty. J. Arthroplast. 2014, 29, 189-192. [CrossRef] [PubMed]

43. Nichols, C.I.; Vose, J.G.; Nunley, R.M. Clinical Outcomes and 90-Day Costs Following Hemiarthroplasty or Total Hip Arthroplasty for Hip Fracture. J. Arthroplast. 2017, 32, S128-S134. [CrossRef]

44. Birkmeyer, J.D.; Siewers, A.E.; Finlayson, E.V.A.; Stukel, T.A.; Lucas, F.L.; Batista, I.; Welch, H.G.; Wennberg, D.E. Hospital Volume and Surgical Mortality in the United States. N. Engl. J. Med. 2002, 346, 1128-1137. [CrossRef] [PubMed]

45. Kaneko, T.; Hirakawa, K.; Fushimi, K. Relationship between peri-operative outcomes and hospital surgical volume of total hip arthroplasty in Japan. Health Policy 2014, 117, 48-53. [CrossRef] [PubMed]

(C) 2020 by the authors. Licensee MDPI, Basel, Switzerland. This article is an open access article distributed under the terms and conditions of the Creative Commons Attribution (CC BY) license (http://creativecommons.org/licenses/by/4.0/). 